\section{'Underachieving' centre has not only struck gold but made good use of it}

Sir - In your News feature "The missionary from Munich" (Nature 405, 10; 2000), Rudi Balling, the incoming director of the German Research Centre for Biotechnology (GBF), calls the centre a "gold mine". Yet you, on the other hand, unkindly refer to it as an "underachiever". Presumably this is intended to mean that the gold mine has not yet been properly exploited.

This is not the case. The the GBF mine has not only produced gold bars, but has turned these into numerous pieces of jewellery and sold them to jewellers. Over many years, scientific contributions from this institute have been published in excellent journals, not least in Nature (see Hattori et al. Nature 405, 311;2000).

The high standard of GBF's research and development is also reflected by an internal evaluation of the German Helmholtz centres, in which the GBF was one of the top-scoring institutes by all the criteria used. In addition to this, the December 99/ January 00 issue of Biotech International compared a long list of biotech companies (such as Bayer and the Roche Group) and research institutions (such as the Max Planck Society) outside the United States: the GBF was ranked twenty-fourth. If normalized according to number of personnel, the GBF, which has only 600 employees, would appear in the top ten. Hardly the performance of an underachiever.

The GBF does have one major drawback. Its full name - Gesellschaft für biotechnologische Forschung mit beschränkter Haftung - doesn't exactly roll off German tongues, let alone those that don't speak the language. How much easier life would be if the GBF were, for example, renamed the Eigen Centre (after Nobel laureate Manfred Eigen, one of its main founders). But although a name change might raise the institute's public profile, high visibility should not be confused with high quality. Helmut Blöcker

Genome Analysis, GBF, Mascheroder Weg 1, D-38124 Braunschweig, Germany

\section{Jumping the gun on mouse gene expression}

Sir - I am writing to correct a statement in the informative News Feature "A silence that speaks volumes" (Nature 404, 804; 2000). The work from my laboratory, published in the paper by Florence Wianny and myself, has shown that dsRNA interference can be effective in both the mouse oocyte and early embryo (see Wianny, F. \& Zernicka-Goetz, M. Nature Cell Biol. 2, 70-75; 2000). We have successfully used the technique to prevent expression of the c-mos gene during oocyte maturation, and of the E-cadherin gene to interfere with formation of the blastocyst when delivered to the one-cell-stage zygote.

We are now planning to attempt to interfere at later stages with the expression of genes that help determine polarity during mouse development. However, although we believe that RNAi offers significant potential for such applications, this idea still remains to be demonstrated. Magdalena Zernicka-Goetz Wellcome/CRC Institute, Tennis Court Road, Cambridge CB2 1QR, UK

\section{Setbacks don't dampen the energy of US physics}

Sir — I read with great interest Colin Macilwain's News report “Budget crisis forces hard choices on US high-energy physics" (Nature 404, 909; 2000). The report goes a long way in describing the general situation of high-energy physics in the United States. Readers may, however, get the wrong impression, both as to its present intellectual health (despite the severe blow of losing the Superconducting Super Collider in 1993), and as to the efforts being made to get back on track as the cartoon accompanying the article so dramatically displays.

High-energy physics here is very vigorous, with activity continuing at the Tevatron (Fermilab), activities under way in neutrino physics, use of the new B-Factory and the development of very large detectors to be used at the large hadron collider in CERN.

New facilities being contemplated include an electron-positron linear collider, a very large hadron collider and a neutrino factory. These facilities address very different aspects of high-energy physics. They are not in competition; they all should be built and — with sufficient international cooperation and an adequately long time frame - they will all be built.

The community, working with international colleagues, is developing a suitable plan for high-energy physics. Arriving at a well-thought-out and widely accepted programme for the future is expected to take a few years; a significant step will be undertaken at a retreat next summer.

With regard to budget realities, a neutrino factory may be attractive as a first step: it fits on several existing sites, it would be of worldwide interest, the accelerator cost can be balanced with detector costs and it can be staged. It would also go a long way towards demonstrating the technologies needed for a possible future muon collider. As we are still improving the design, it is premature to say if it will ultimately cost more or less than the $\$ 1$ billion stated in your article. However, our first-draft design could be built in a few increments, each one costing under $\$ 1$ billion, and each addressing new, and most interesting, physics. Andrew M. Sessler

The Neutrino Factory and Muon Collider Collaboration, Lawrence Berkeley National Laboratory, University of California, Berkeley, California 94720, USA

\section{How the GM industry writes its own rules}

Sir - Colin Macilwain's News story about the US Food and Drug Administration 'reforms' in the supervision of genetically modified food (Nature 405, 108; 2000) tells only part of the story.

Not only did the announcement "not include any mandatory requirement for the labelling of GM foods" - it did not include any requirement for pre-marketing scientific assessment by the government either.

As a result, we have no real supervision of the industry here. All the FDA did was to make mandatory the 'consultations' which had previously been optional (not a tough demand, since in every case so far, the companies had met FDA officials voluntarily anyway).

The information that is to be placed on the FDA's website will be highly censored, because the United States enforces strict rules protecting proprietary business information. This outweighs any notion of the public's right to know what we are putting in our bodies.

The agency's plan to develop guidelines for voluntary labelling is nice but unnecessary, because our First Amendment guarantees that, as long as a statement is truthful, we don't really need government permission to say it.

This is an exercise in how to tread water and make it appear that you are swimming. Philip L. Bereano

Council for Responsible Genetics, 5 Upland Road, Cambridge, Massachusetts 02140, USA

\section{W. D. Hamilton memorial}

Sir - A non-religious memorial event for W. D. Hamilton (see Nature 404, 828; 2000) will be held in the chapel of New College, Holywell Street, Oxford, on 1 July 2000 at 2.30 p.m. All are welcome to attend.

Richard Dawkins

New College, Oxford OX1 3BN, UK 